\title{
An in-vitro biomechanical study of different fixation techniques for the extended trochanteric osteotomy in revision THA
}

\author{
Zhonglin Zhu', Hui Ding ${ }^{1}$, Hongyi Shao ${ }^{2}$, Yixin Zhou² and Guangzhi Wang ${ }^{1 *}$
}

\begin{abstract}
Background: The wire fixation and the cable grip fixation have been developed for the extended trochanteric osteotomy (ETO) in the revision of total hip arthroplasty (THA). Many studies reported the postoperative performance of the patients, but with little quantitative biomechanical comparison of the two fixation systems.

Methods: An in-vitro testing approach was designed to record the loosening between the femoral bed and the greater trochanter after fixations. Ten cadaveric femurs were chosen in this study. Each femur underwent the THA, revision by ETO and fixations. The tension to the greater trochanter was from 0 to $500 \mathrm{~N}$ in vertical and lateral direction, respectively. The translation and rotation of the greater trochanter with respect to the bony bed were captured by an optical tracking system.

Results: In the vertical tension tests, the overall translation of the greater trochanter was observed $0.4 \mathrm{~mm}$ in the cable fixations and $7.0 \mathrm{~mm}$ in the wire fixations. In the lateral tension tests, the overall motion of the greater trochanter was $2.0 \mathrm{~mm}$ and $1.2^{\circ}$ in the cable fixations, while it was $6.2 \mathrm{~mm}$ and $5.3^{\circ}$ in the wire fixations. The result was significantly different between the two fixation systems.
\end{abstract}

Conclusions: The stability of the proximal femur after ETO using different fixations in the revision THA was investigated. The cable grip fixation was significantly more stable than the wire fixation.

Keywords: Tension, Fixation, Biomechanics, Extended trochanteric osteotomy

\section{Background}

The extended trochanteric osteotomy (ETO), has proved to be an effective method in many revision total hip arthroplasty (THA) and complicated primary THA [1]. Wires and Cables were applied in the early ETO fixation [1]. Later the cable fixation system was improved to utilize a claw plate to strengthen the greater trochanter, which was called the cable grip system. The latest fixations were reported, such as using suture cord and nonmetallic cable $[2,3]$. ETO has many advantages, such as larger exposure during operation, lower risk of the femoral facture, and larger contact area for healing of the osteotomized bone, etc. [4-8]. Due to the failures of the fixations in biomechanical stability, the fragment was

\footnotetext{
* Correspondence: wgz-dea@tsinghua.edu.cn

'Department of Biomedical Engineering, Tsinghua University, Beijing, China Full list of author information is available at the end of the article
}

observed loosing from the femoral bed after the ETO $[1,9,10]$.

There were several techniques to investigate the stability of the fixed proximal femur after the ETO, including clinical postoperative assessment [8,11-14], imaging studies [15-17], computational model analysis [18], and biomechanical tests [4,5,19-21]. Imaging studies has been widely used to measure the in-vivo displacement of the fragments. The limitation was that only the translations of the fragments could be measured, the forces acted to the bone were still unknown. The in-vitro biomechanical tests were able to simulate some of the invivo biomechanical conditions and study the motion of fragment when different loads were applied $[4,5]$.

In this study, an in-vitro biomechanical testing approach was used to measure the stability of different fixations in the ETO. The micro-motion of the fixed fragment was captured when an increasing tension was

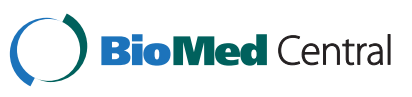

(c) 2013 Zhu et al.; licensee BioMed Central Ltd. This is an Open Access article distributed under the terms of the Creative Commons Attribution License (http://creativecommons.org/licenses/by/2.0), which permits unrestricted use, distribution, and reproduction in any medium, provided the original work is properly cited. 
applied to the greater trochanter. The stability of the proximal femur using different fixation techniques was compared.

\section{Methods \\ Materials}

Ten fresh-frozen cadaveric adult femurs (4 left, 6 right, 5 male, 5 female, average age 31) with similar geometric shape were chosen in this experiment which was approved by the institutional research board of the Beijing Jishuitan hospital. All specimens were anatomically normal, good in bone quality and without a history of a malignant lesion. The specimen was thawed at room temperature before testing. Each specimen was disarticulated from the acetabulum and tibia. After removal of the surrounding tissues, the femur was cut to remain 2/ 3 length in the proximal side [5]. The distal side was potted to a cylindrical mold filled with denture base resin (Shanghai New Century Dental Materials CO., LTD), to facilitate clamping tightly in the material testing system $[5,20]$. Surgical instruments for the THA and ETO were used. Implanted prosthesis was prepared for each femur (The ECHELON ${ }^{\diamond}$ Revision Hip System, Smith \& Nephew). 18-gauge wires and cerclage cable (w/crimp, $1.8 \mathrm{~mm}$, length $635 \mathrm{~mm}$, Zimmer) were used in the fixations. A short claw plate $(50.8 \mathrm{~mm}$ length, $22.1 \mathrm{~mm}$ width, Zimmer) and a long claw plate (121.4 $\mathrm{mm}$ length, $22.1 \mathrm{~mm}$ width, Zimmer), were combined with cables to help fix the resected greater trochanter. In order to maintain the constant material property of the bone, the room temperature was controlled the same and the moisturizing process was performed during the experiment.

\section{Experiment preparation}

A series of THA and ETO were performed to the femur by the same experienced surgeon.
1) Osteotomy: The neck of the intact proximal femur was resected to implant the THA prosthesis. Then the greater trochanter was cut extendedly to remove the previous implant in a revision THA. The vertical cuts were $13 \mathrm{~cm}$ at the anterior and posterior side of the proximal femur (Figure 1). The horizontal cut was one third of the girth and joined both sides of the vertical cuts $[7,20,22]$. The piece of the extended greater trochanter was separated from the femoral bed. The THA prosthesis was replaced by an implant for revision.

2) Fixation: Each femur underwent a series of five fixations in a random order, which were 2-wires fixation (F1), 3-wires fixation (F2), a short claw plate fixation with 2 wires and 2 cables (F3), a short claw plate fixation with 4 cables (F4), and a long claw plate fixation with 4 cables (F5) (Figure 1). The short claw plate was attached to the separated bone by 2 cables. The long claw plate fixation combined 4 cables was able to fix the whole fragment. However, the short claw plate combined 2 cables was not long enough, so additional 2 wires or 2 cables were used. The wires were tightened manually by pliers. The cables were tightened semi-automatically by a synthesis tensioner with a recommended $50 \mathrm{~kg}$ of tension [5].

3) Measurement Devices: The three dimensional (3D) motion between the femoral bed and the fragment was tracked by an Optotrak Certus ${ }^{\mathrm{Tm}}$ optoelectronic camera system (Northern Digital, Waterloo, Canada). A servo hydraulic material testing system (MTS858, with $25 \mathrm{kN} \pm 5 \mathrm{~N}$ axial force load cell, 250 Nm torque capacity, Eden Prairie, MN USA) was used to supply a tension from $0 \mathrm{~N}$ to $500 \mathrm{~N}$ with an increment of $1 \mathrm{~N}$ per second. The sampling rate for motion data was set to $10 \mathrm{~Hz}$. A self-developed minitype infrared active marker connected to the NDI system was used (Figure 2), which was validated as well as the NDI standard markers with a

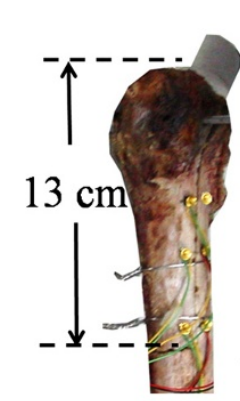

F1

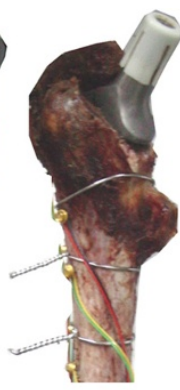

F2

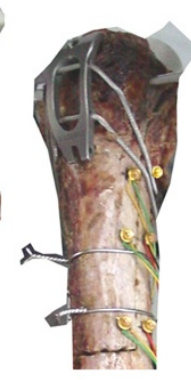

F3

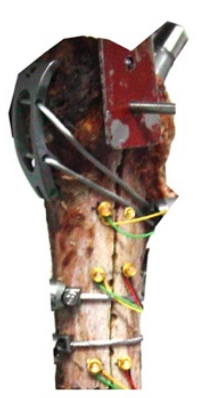

F4

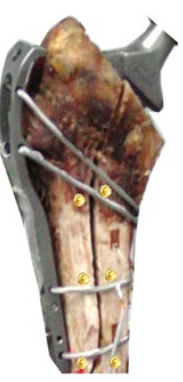

F5

Figure 1 Five fixations: 2-wires fixation (F1), 3-wires fixation (F2), a short claw plate fixation with 2 wires and 2 cables (F3), a short claw plate fixation with 4 cables (F4), and a long claw plate fixation with 4 cables (F5). 


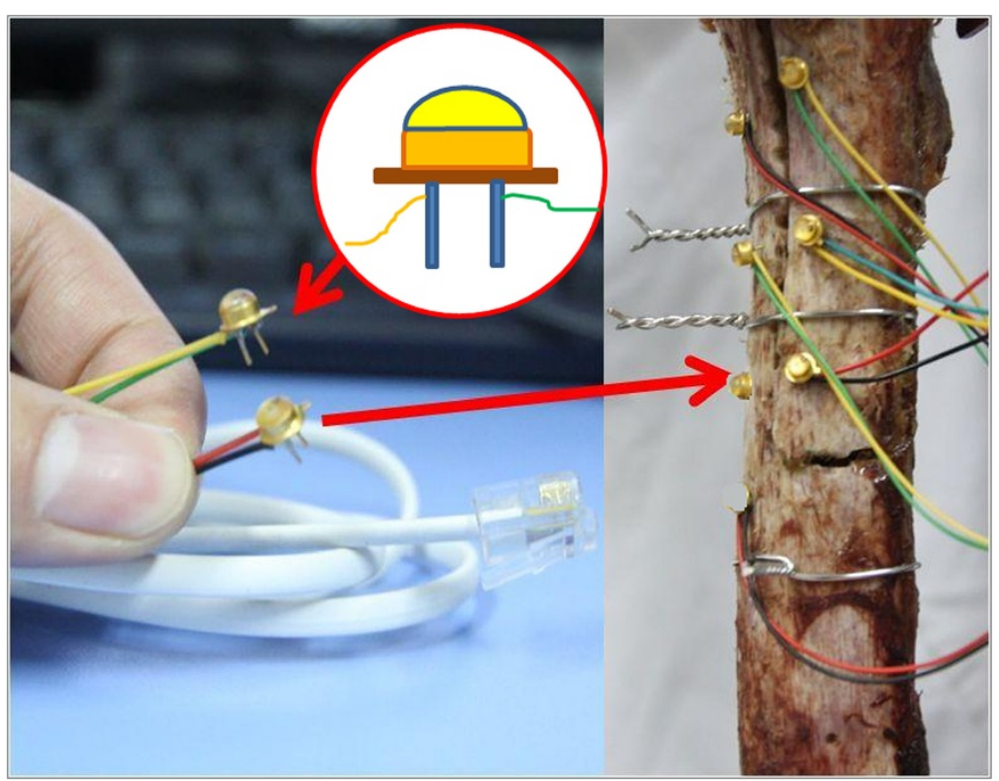

Figure 2 A minitype infrared active marker was used to track the 3D motion in space.

root-mean-square (RMS) accuracy of $0.1 \mathrm{~mm}$. There were two roots on each maker to mount to the bone. Each root was less than $1 \mathrm{~mm}$ in diameter and 4-5 $\mathrm{mm}$ in length. Eight markers were used to track the motion of the femoral bed $(\mathrm{A}, \mathrm{B}, \mathrm{C})$, the cut bone (D, E, F) and the MTS actuator $(G, H)$ (Figure 3 (a)). The Marker D was $10 \mathrm{~mm}$ from the horizontal cut. The cluster of three markers on the same side was placed non-linear. The markers were placed in similar position on different specimens. Two makers that attached to the MTS actuator were used to synchronize the MTS and the motion tracking system.

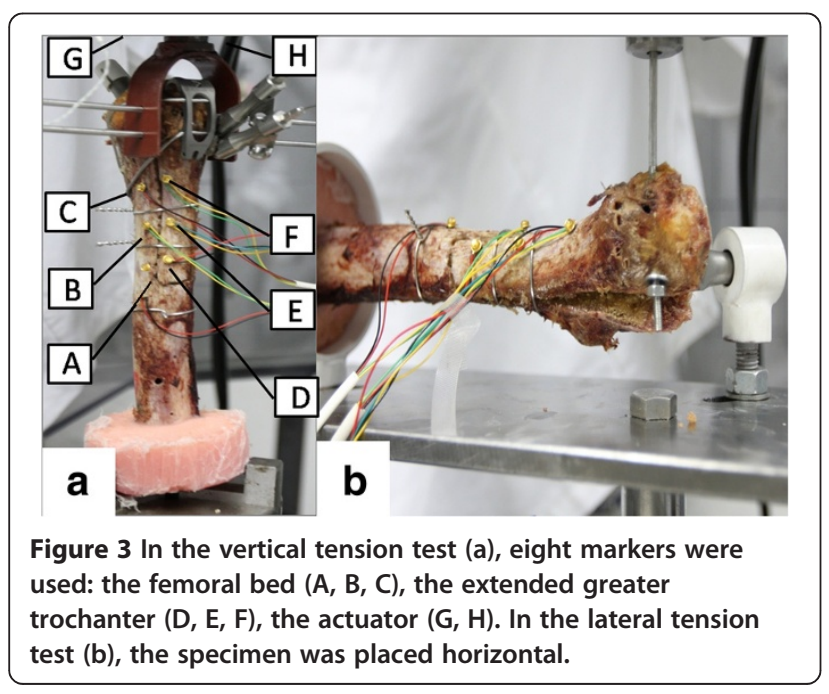

\section{Testing}

The purpose of the test was to simulate the in-vivo mechanical environment of the proximal femur after ETO revision. The muscles attached to the greater trochanter generated a large tension during some tasks, such as lifting-up of the leg. The directions of the tensions were measured mainly in the vertical the postlateral direction. The vertical tension on the greater trochanter guaranteed the balance of the hip joint during standing pose. The lateral tension pointed from anterior to posterior was found during standing from a seated position or climbing stairs (Figure 3 (b)). $500 \mathrm{~N}$ was chosen as the maximum tension in our test, similar to the previous study [5].

In the vertical tension test, the resinous cylinder was fixed on the MTS, and the greater trochanter was clamped by the vise on the actuator (Figure 3 (a)). In the lateral tension test, the implant and the resinous cylinder was fixed by a test fixture (Figure 3(b)). Before testing, a $50 \mathrm{~N}$ tension load by MTS was performed to eliminate the gap existed in fixations and connections. After the whole fixed femur was trained to a steady state, the tension was relaxed to zero. During the test, the actuator generated a tension from 0 to $500 \mathrm{~N}$ with an increment of $1 \mathrm{~N}$ per second, meanwhile the NDI system started to collect the motion data of the markers. After a pulling test the stability of the fixed femur was destroyed. The wire or cable fixations were loosened and required fixation again. The force and motion data was recorded for one kind of fixations after more than 3 trials of preconditioning biomechanical tests. The 3D motion of all makers were collected and recorded by the NDI First 
Principles software associated with NDI's Optotrak Certus $^{\text {Tw. }}$. The synchronous force data from $0 \mathrm{~N}$ to $500 \mathrm{~N}$ were collected by Model 793.10 Multipurpose TestWare associated with MTS.

\section{Data processing}

The motion of the greater trochanter relative to the femoral bed was calculated in translations and rotations $\{t x, t y, t z, \alpha, \beta, \gamma\}$ [23]. The deformation of each tracked object was observed less than $0.5 \mathrm{~mm}$, so the femoral bed and the greater trochanter were approximately rigid bodies. During data processing, all motion data was presented in the local coordinate system $(\mathrm{O}-\mathrm{XYZ})$ of the femoral bed (Figure 4). The origin $(\mathrm{O})$ of the femoral bed was $6.5 \mathrm{~cm}$ from the horizontal cut on the line $\mathrm{AC}$ (Figure 3(a)). The $\mathrm{Y}$ axis pointed to the marker $\mathrm{C}$. The $\mathrm{X}-\mathrm{Y}$ plane was decided by all the six markers (from A to F) on the bone to approximate the coronal plane using the least square method. The $\mathrm{X}$ axis pointed to the anterior side of the femur. The $\mathrm{Z}$ axis was decided using the right-handed coordinate system definition. The point P1 on the proximal end of the extended greater trochanter was $13 \mathrm{~cm}$ from the horizontal cut on the line DF (Figure 3(a)).

In Figure 4(a), the translation along the $\mathrm{Y}$ axis was much larger than the translations $(<0.3 \mathrm{~mm})$ in other two directions (Figure 4 (a)). Meanwhile all rotations were small $(<0.3$ degree). In this study, the displacement of P1 along the $\mathrm{Y}$ axis was calculated to present the translations of the fragment in the vertical tension (F1) test. In Figure $4(\mathrm{~b})$, the translation along the $\mathrm{Z}$ axis and the rotation along the $\mathrm{X}$ axis were much larger than the other translations and rotations. So in the lateral tension (F2) test, the motion of the fragment was presented by the displacement of $\mathrm{P} 1$ along the $\mathrm{Z}$ axis, and the rotation was along the $X$ axis in Figure 4(b). The motion was analyzed from $100 \mathrm{~N}$ to $500 \mathrm{~N}$ with an interval of $100 \mathrm{~N}$.

The result of the five different fixations was analyzed statistically using the SPSS 16.0 software. One-way analysis of variance followed by post hoc pairwise comparisons ( Student-Newman-Keuls ) was used. Differences were considered significant at $\boldsymbol{P}<\boldsymbol{0 . 0 5}$.

\section{Results}

The motion in the vertical tension test was shown in Figure 5. All of the translations increased monotonously while the tension increased to $500 \mathrm{~N}$. The statistical analysis of all fixations under the load of $500 \mathrm{~N}$ was given in Figure 5. The translation was $7.4 \pm 4.0 \mathrm{~mm}$ in the test of $\mathrm{F} 1$ and $6.7 \pm 5.2 \mathrm{~mm}$ in the test of F2 with no significant different between them. In the test of cable grip fixations under $500 \mathrm{~N}$, the translation was $0.4 \pm 0.3 \mathrm{~mm}(\mathrm{~F} 3), 0.3$ $\pm 0.3 \mathrm{~mm}$ (F4), and $0.4 \pm 0.1 \mathrm{~mm}$ (F5) respectively. No significant difference was found among them. When the wire fixations (F1, F2) were compared to the cable grip
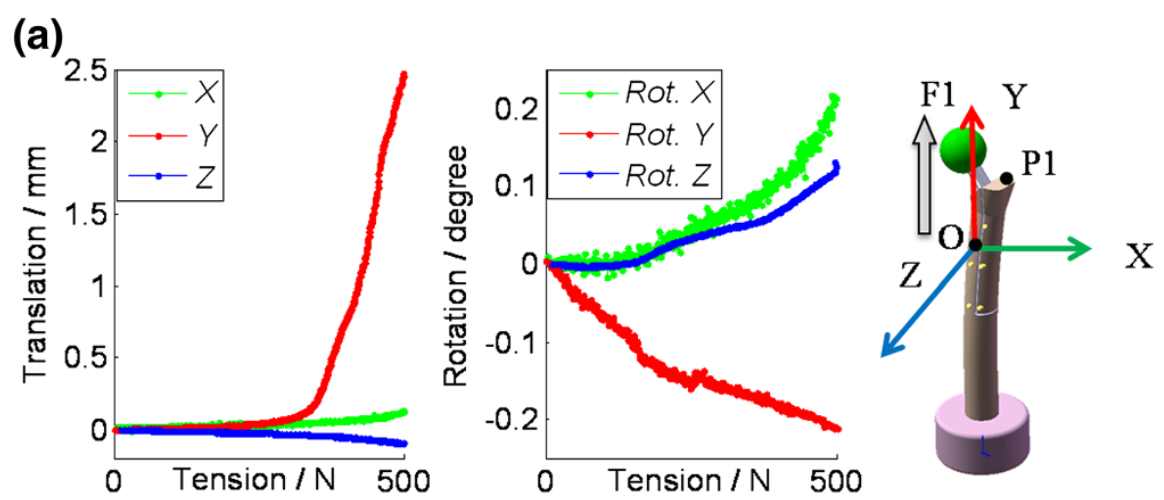

(b)
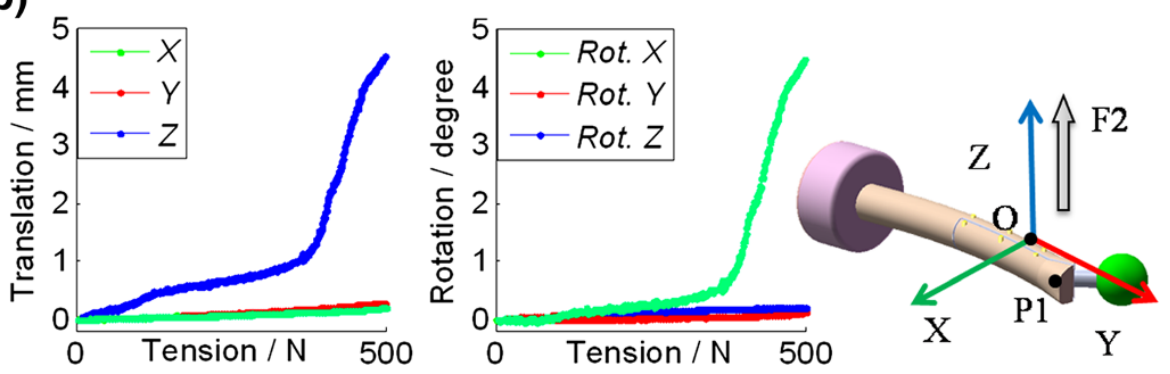

Figure 4 The local coordinate system of the femoral bed: the origin was $6.5 \mathrm{~cm}$ from horizontal cut; The X-Y plane was decided by all the 6 markers on the bone. The 6 DOF of motion of the extended greater trochanter in one test was shown in the vertical tension test (a) and the lateral tension test (b). 


\begin{tabular}{|c|c|c|c|c|c|c|c|}
\hline \multicolumn{6}{|c|}{ The result of the five fixations in the vertical tension test } & & \multirow[b]{2}{*}{${ }_{*}^{*}$} \\
\hline \multirow{2}{*}{ Tension/N } & \multicolumn{5}{|c|}{ Translation/mm mean(SD) } & & \\
\hline & F1 & F2 & F3 & F4 & F5 & & \\
\hline 100 & $0.1(0.4)$ & $0.0(0.1)$ & $0.0(0.0)$ & $0.0(0.0)$ & $0.0(0.0)$ & & * \\
\hline 200 & $1.0(1.4)$ & $0.7(0.4)$ & $0.1(0.1)$ & $0.0(0.0)$ & $0.0(0.0)$ & & * \\
\hline 300 & $2.5(2.4)$ & $2.3(1.4)$ & $0.2(0.2)$ & $0.1(0.2)$ & $0.1(0.0)$ & 6 & \\
\hline 400 & $4.6(3.1)$ & $4.2(2.7)$ & $0.2(0.3)$ & $0.2(0.2)$ & $0.2(0.1)$ & 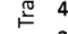 & \\
\hline 500 & $7.4(4.0)$ & $6.7(5.2)$ & $0.4(0.3)$ & $0.3(0.3)$ & $0.4(0.1)$ & & 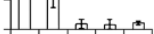 \\
\hline $\begin{array}{c}500 \\
\text { (overall mean) }\end{array}$ & & & & $0.4 \mathrm{~mm}$ & & & $\begin{array}{l}F 1 \text { F2 F3 F4 F5 } \\
\text { ension of } 500 \mathrm{~N}\end{array}$ \\
\hline
\end{tabular}

Figure $\mathbf{5}$ The result of the five fixations in the vertical tension test.

system (F3, F4 and F5), a significant difference was found $(\boldsymbol{P} \leqq 0.001)$.

The result from the lateral tension test was shown in Figure 6. All of the translations and rotations increased monotonously during testing. The statistical analysis of all fixations under the load of $500 \mathrm{~N}$ was given in Figure 6. It was $8.9 \pm 7.6 \mathrm{~mm}$ in translation and $7.0 \pm$ 5.5 degree in rotation in the test of F1, and $3.5 \pm 2.5$ $\mathrm{mm}$ and $3.6 \pm 3.2$ degree in the test of F2, with no significant difference between them. Under the tension of $500 \mathrm{~N}$, the translation was $1.8 \pm 1.6 \mathrm{~mm}, 1.9 \pm 1.5 \mathrm{~mm}$, and $2.3 \pm 1.4 \mathrm{~mm}$ for the F3, F4 and F5, respectively. The rotation was $0.9 \pm 0.5$ degree, $1.0 \pm 0.7$ degree, and $1.6 \pm 1.0$ degree for the F3, F4 and F5, respectively. No significant difference was found among them. When the wire fixations (F1) was compared with the cable grip fixations (F3, F4 and F5), a significant difference was found $(\boldsymbol{P} \leqq \boldsymbol{0 . 0 1 5})$ in both translation and rotation. There was significant difference in rotation when the test of F2 was compared to the short claw plate fixations (F3, F4).

\section{Discussion}

The biomechanical stability of different fixations used in ETO during THA revision was investigated in this study. The stability of the cable grip fixations was better than the wire fixations.

In the vertical tension test, the experiment simulated the in-vivo abductors muscles of hip acting on the greater trochanter during standing. Kang et al. reported that $2.6 \mathrm{~mm}$ in average was observed after the ETO using 2-wires fixation [24]. Mardones et al. reported that the vertical translation was more than $5 \mathrm{~mm}$ in $7 \%$ of all patients [15]. In our study, the result was $7.4 \pm 4.0 \mathrm{~mm}$ in the fixation using 2 wires and $6.7 \pm 5.2 \mathrm{~mm}$ in the fixation using 3 wires. Nercessian et al. gave a standard of $2.5 \mathrm{~mm}$ in translation for the clinical assessment [12]. However, the average translations in the wire fixations (F1 and F2) were both larger than $2.5 \mathrm{~mm}$ after the tension of $300 \mathrm{~N}$ in this study. The maximum translation was about $0.4 \mathrm{~mm}$ in the claw plate fixations (F3, F4, and F5). In general, the cable grip fixations were better

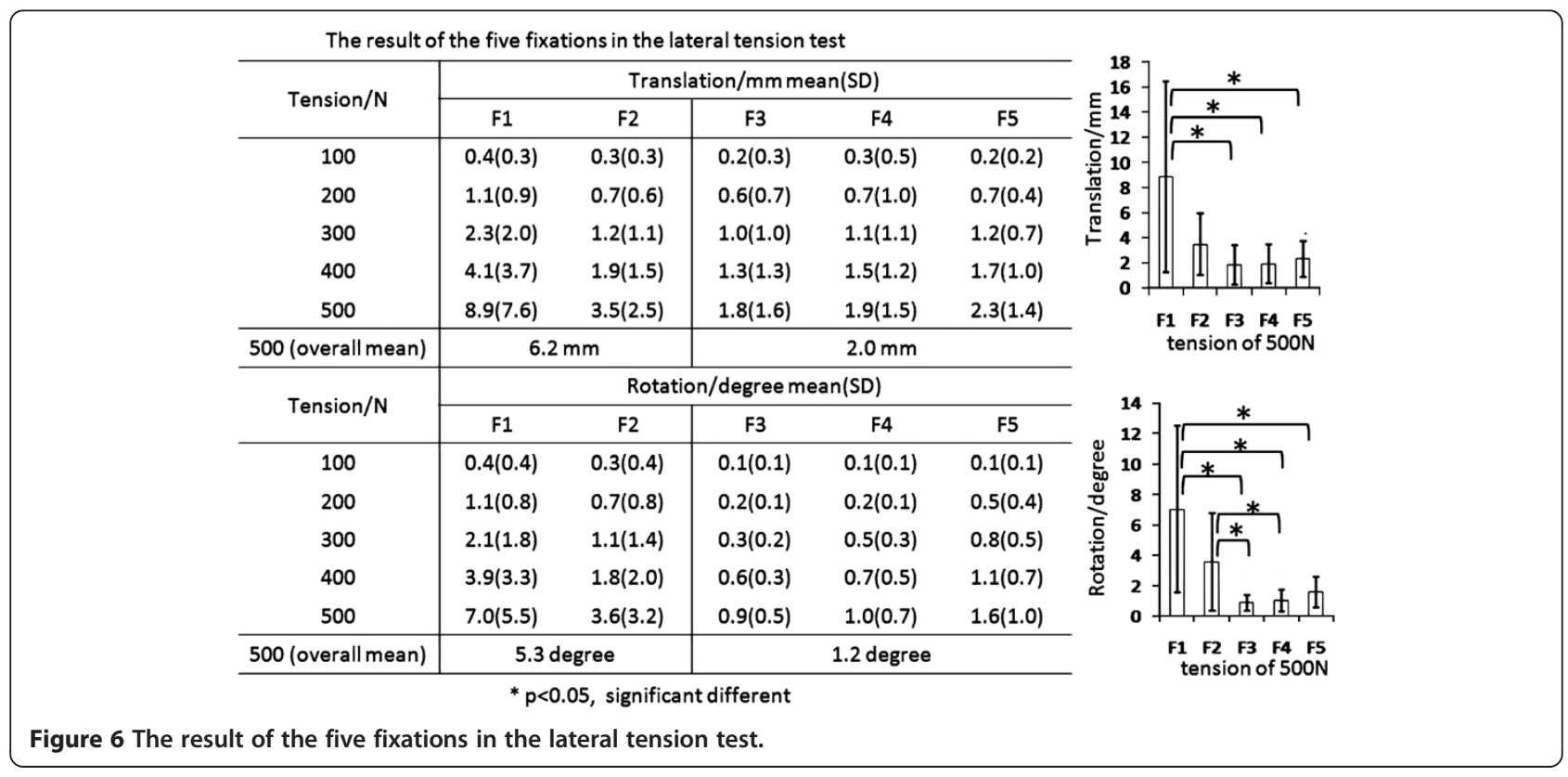


in stability than the wire fixations. Considering the surgical tools for fixations, all cables were tightened to 50 $\mathrm{Kg}$ of tension, but the wire was fixed by pliers where the tightening degree was not easy to control. This might be the reason that the standard deviation of the translation was observed larger in the wire fixations. The cables that passed the lesser trochanter were able to resist the vertical tension to provide a more stable fixation.

The translation and rotation were investigated between the femoral bed and the greater trochanter when a lateral tension was applied, which was investigated in few previous studies [20]. In this study, the rotation was observed 7.0 degree in the wire fixations under $500 \mathrm{~N}$. Noble et al. observed that the stability against torsion (similar to the lateral tension) was decreased by 19\% after the ETO, compared to the intact group [20]. So higher risk of nonunion or fractures might occur when lateral tension was applied to the greater trochanter. In this study, the result indicated that more wires used for fixation was able to reduce the rotation.

The result from this study was consistent with the clinical outcomes $[7,13]$. Shao et al. pointed out that the cable grip fixations were more stable than wire fixations. The claw plate could prevent the greater trochanter from sliding up and rotating [7]. Barrack et al. found that in the cable grip fixations the fracture of fixtures, nonunion and limping, were less than using the wire fixations [13]. In summary, the cable grip fixations were better in stability.

There were certain limitations in the current study. One limitation was that five different fixations were performed on the same femur due to the difficulty of acquiring more fresh cadavers in this study. In order to reduce the micro-damage to the cut surface, $500 \mathrm{~N}$ was chosen as the maximum loads. However, the microdamage might not be ignorable, especially in a failure test such as the peak value of $970 \mathrm{~N}$ reported by Schwad et al. [5]. So it's better to perform only one kind of mechanical test on one specimen. The second limitation was that the loading mode was simplified. Multiple loading modes such as loading on the femoral head would be more physiologic to simulate some biomechanical status in daily life activities, which will be used in our future study.

\section{Conclusions}

An in-vitro biomechanical study of the stability was designed to compare the different fixations for ETO in the revision THA. The micro-motion between the fragment and the femoral bed was measured. The cable grip fixations were better in stability than the wire fixations. The comparison between the two fixation techniques was able to provide useful information to both surgeons and patients. In future studies, more specimens and multiple loading modes will be applied to test the stability of the proximal femur after revisions.

Competing interests

The authors declare that they have no competing interests.

\section{Authors' contributions}

All authors were fully involved in the study and preparation of the manuscript. The manuscript has been read and agreed by all authors.

\section{Acknowledgment}

This work was supported in part by the National Basic and Key Technologies R \& D Program of China (2011CB707701, 2011BAF01B03), and the Ph.D. Programs Foundation of Ministry of Education of China (20090002110023, 20110002110024 ). Thanks for the help of Mr. Qinghua Xue, Mr. Xiao Dang, Mr. Wenjun Li and Mr. Jianfeng Tao during experiment.

\section{Author details}

${ }^{1}$ Department of Biomedical Engineering, Tsinghua University, Beijing, China ${ }^{2}$ Bejing Ji Shui Tan hospital, the 4th Medical College of Peking University, Beijing, China.

Received: 12 October 2011 Accepted: 3 April 2013

Published: 9 April 2013

\section{References}

1. Jarit GJ, Sathappan SS, Panchal A, Strauss E, Di Cesare PE: Fixation systems of greater trochanteric osteotomies: biomechanical and clinical outcomes. J Am Acad Orthop Surg 2007, 15:614-624.

2. Kuruvalli RR, Landsmeer R, Debnath UK, Suresh SP, Thomas TL: A new technique to reattach an extended trochanteric osteotomy in revision THA using suture cord. Clin Orthop Relat Res 2008, 466:1444-1448.

3. Ting NT, Wera GD, Levine BR, Della Valle CJ: Early experience with a novel nonmetallic cable in reconstructive hip surgery. Clin Orthop Relat Res 2010, 468:2382-2386.

4. Khanna G, Bourgeault CA, Kyle RF: Biomechanical comparison of extended trochanteric osteotomy and slot osteotomy for femoral component revision in total hip arthroplasty. Clin Biomech (Bristol, Avon) 2007, 22:599-602.

5. Schwab JH, Camacho J, Kaufman K, Chen Q, Berry DJ, Trousdale RT: Optimal fixation for the extended trochanteric osteotomy: a pilot study comparing 3 cables vs 2 cables. J Arthroplasty 2008, 23:534-538.

6. Archibeck MJ, Rosenberg AG, Berger RA, Silverton CD: Trochanteric osteotomy and fixation during total hip arthroplasty. J Am Acad Orthop Surg 2003, 11:163-173

7. Shao H, Liu Z, Zhou Y, Liu J: Application of extended trochanteric osteotomy in hip joint revision. Orthopedic journal of China 2009, 17:

8. Zarin JS, Zurakowski D, Burke DW: Claw plate fixation of the greater trochanter in revision total hip arthroplasty. J Arthroplasty 2009, 24:272-280.

9. Peters PC Jr, Head WC, Emerson RH Jr: An extended trochanteric osteotomy for revision total hip replacement. J Bone Joint Surg Br 1993, 75:158-159.

10. Lim SJ, Moon YW, Park YS: Is extended trochanteric osteotomy safe for use in 2-stage revision of periprosthetic hip infection? J Arthroplasty 2011, 26:1067-1071

11. Kavanagh BF, Ilstrup DM, Fitzgerald RH Jr: Revision total hip arthroplasty. J Bone Joint Surg Am 1985, 67:517-526.

12. Nercessian OA, Newton PM, Joshi RP, Sheikh B, Eftekhar NS: Trochanteric osteotomy and wire fixation: a comparison of 2 techniques. Clin Orthop Relat Res 1996, 333:208-216.

13. Barrack RL, Butler RA: Current status of trochanteric reattachment in complex total hip arthroplasty. Clin Orthop Relat Res 2005, 441:237-242.

14. Lakstein D, Kosashvili Y, Backstein D, Safir O, Lee P, Gross AE: The long modified extended sliding trochanteric osteotomy. Int Orthop 2011, 35:13-17.

15. Mardones R, Gonzalez C, Cabanela ME, Trousdale RT, Berry DJ: Extended femoral osteotomy for revision of hip arthroplasty: results and complications. J Arthroplasty 2005, 20:79-83. 
16. Hop JD, Callaghan JJ, Olejniczak JP, Pedersen DR, Brown TD, Johnston RC: The Frank Stinchfield award. Contribution of cable debris generation to accelerated polyethylene wear. Clin Orthop Relat Res 1997, 344:20-32.

17. Chen WM, McAuley JP, Engh CA Jr, Hopper RH Jr, Engh CA: Extended slide trochanteric osteotomy for revision total hip arthroplasty. J Bone Joint Surg Am 2000, 82:1215-1219.

18. Busch CA, Charles MN, Haydon CM, Bourne RB, Rorabeck CH, Macdonald SJ, McCalden RW: Fractures of distally-fixed femoral stems after revision arthroplasty. J Bone Joint Surg Br 2005, 87:1333-1336.

19. Chassin EP, Silverton CD, Berzins A, Rosenberg AG: Implant stability in revision total hip arthroplasty: allograft bone packing following extended proximal femoral osteotomy. J Arthroplasty 1997, 12:863-868.

20. Noble AR, Branham DB, Willis MC, Owen JR, Cramer BW, Wayne JS, Jiranek WA: Mechanical effects of the extended trochanteric osteotomy. J Bone Joint Surg Am 2005, 87:521-529.

21. Zhu Z, Ding H, Dang X, Shao H, Zhou Y, Wang G: Tension and motion measurement for extended trochanteric osteotomy with different fixation methods. Conf Proc IEEE Eng Med Biol Soc 2009, 2009:5255-5258.

22. MacDonald SJ, Cole C, Guerin J, Rorabeck CH, Bourne RB, McCalden RW: Extended trochanteric osteotomy via the direct lateral approach in revision hip arthroplasty. Clin Orthop Relat Res 2003, 417:210-216.

23. Zhu Z, Li G: An automatic 2D-3D image matching method for reproducing spatial knee joint positions using single or dual fluoroscopic images. Comput Methods Biomech Biomed Engin 2012, 15:1245-1256.

24. Kang P, Pei F, Shen B, Zhou Z, Yang J: Extended trochanteric osteotomy for removal of solidly-fixed femoral implants in total hip revision. Chinese journal of surgery 2009, 47:177-180.

doi:10.1186/1749-799X-8-7

Cite this article as: Zhu et al:: An in-vitro biomechanical study of different fixation techniques for the extended trochanteric osteotomy in revision THA. Journal of Orthopaedic Surgery and Research 2013 8:7.

\section{Submit your next manuscript to BioMed Central and take full advantage of:}

- Convenient online submission

- Thorough peer review

- No space constraints or color figure charges

- Immediate publication on acceptance

- Inclusion in PubMed, CAS, Scopus and Google Scholar

- Research which is freely available for redistribution 